\title{
Electromyographic normalization of vastus lateralis and biceps femoris co-contraction during gait of elderly females
}

\author{
Normalização eletromiográfica da co-contração do vasto \\ lateral e bíceps femoral durante a marcha de idosas
}

\section{Katy Andrade Monteiro Zacaron ${ }^{[a, b]}$, João Marcos Domingues Dias ${ }^{[b, c]}$, Mariana Asmar Alencar ${ }^{[b, d]}$, Luane Landim de Almeida ${ }^{[\mathrm{e}]}$, Carlos Alberto Mourão-Júnior ${ }^{[a]}$, Rosângela Correa Dias ${ }^{[\mathrm{b}, \mathrm{c}]^{*}}$}

[a] Universidade Federal de Juiz de Fora (UFJF), Juiz de Fora, MG, Brazil

[b] Universidade Federal de Minas Gerais (UFMG), Belo Horizonte, MG, Brazil

[c] Universidade Federal de São Paulo (UNIFESP), São Paulo, SP, Brazil

[d] Universidade Fundação Mineira de Educação e Cultura (FUMEC), Belo Horizonte, MG, Brazil

[e] Faculdade de Ciências Médicas e da Saúde de Juiz de Fora (FCMS/JF), Juiz de Fora, MG, Brazil

\begin{abstract}
Introduction: Analyze muscle co-contraction using electromyographic signals, which are normalized to compare individuals, muscles and studies. Maximum voluntary isometric contraction (MVIC) and peak electrical activity (PEA) during movement are the most widely used forms of normalization. Objective: Compare inter-subject variability and investigate the association between the co-contraction indices of the vastus lateralis and biceps femoris during gait, normalized by MVIC and PEA. Methods: Thirty elderly women, aged $70.33 \pm 3.69$ years took part. Electrical muscle activity during MVIC and gait was recorded using a Biopac MP100 electromyograph. MVIC was performed in a Biodex isokinetic dynamometer. For normalization, the signals were divided by the Root Mean Square values of MVIC and PEA of gait. Results: The coefficient of variation of non-normalized data was $69.3 \%$, and those normalized by PEA and MVIC were $30.4 \%$ and
\end{abstract}

\footnotetext{
"KAMZ: MS, e-mail: katy.andrade@ufjf.edu.br JMDD: PhD, e-mail: jmdd@ufmg.br MAA: PhD, e-mail: masmaralencar@yahoo.com.br LLA: BS, e-mail: lua_landim@hotmail.com CAMJ: PhD, e-mail: camouraojr@gmail.com RCD: PhD, e-mail: rcd@ufmg.br
} 
48.9\% respectively. Linear regression analysis resulted in a prediction model: PEA $=0.04+0.16 \times$ MVIC. The goodness of fit of the regression model was statistically significant $(p=0.02)$. The confidence interval $(95 \%$ $\mathrm{CI}$ ) for the intercept was between 0.02 and 0.29 and for MVIC between 0.03 and 0.06 . Conclusions: The data normalized by PEA showed less variation than those normalized by MVIC. A 100\% variation in data normalized by MVIC resulted in a $16 \%$ variation in data normalized by PEA, while variation in normalization by MVIC accounts for $17 \%$ of the variation in normalization by PEA and vice versa.

Keywords: Muscle Contraction. Isometric Contraction. Reproducibility of Results. Muscle Strength Dynamometer. Electromyography.

\title{
Resumo
}

\begin{abstract}
Introdução: Analisa-se co-contração muscular através dos sinais eletromiográficos, os quais são normalizados para permitir comparação entre indivíduos, músculos e estudos. A contração voluntária máxima isométrica (CVMi) e o pico da atividade elétrica (PAE) durante o ato motor são as formas de normalização mais utilizadas. Objetivos: Comparar a variabilidade inter-sujeitos e investigar a associação entre os índices de co-contração, do vasto lateral e bíceps femoral durante a marcha, normalizados pela CVMi e PAE. Métodos: Participaram 30 idosas, idade 70,33 \pm 3,69 anos. A atividade elétrica dos músculos durante a CVMi e na marcha foi registrada pelo eletromiógrafo Biopac MP100. A CVMi foi realizada no dinamômetro isocinético Biodex. Para normalização, os sinais foram divididos pelos valores do Root Mean Square da CVMi e pelo PAE da marcha. Resultados: O coeficiente de variação dos dados não normalizados foi 69,3\%, e dos normalizados pelo PAE e CVMi foram 30,4\% e 48,9\% respectivamente. A análise de regressão linear produziu o modelo de predição: PAE =0,04 +0,16 x CVMi. $O$ ajuste do modelo de regressão foi estatisticamente significante $(p=0,02)$. $O$ intervalo de confiança (IC95\%) para o intercepto foi de 0,02 a 0,29 e para a CVMi foi de 0,03 a 0,06. Conclusão: Os dados normalizados pelo PAE apresentaram menor variação que os normalizados pela CVMi. Uma variação de $100 \%$ nos dados normalizados pela CVMi resulta em 16\% de variação nos dados normalizados pelo PAE, enquanto a variação da normalização pela CVMi é responsável por 17\% de variação da normalização pelo PAE e vice-versa.
\end{abstract}

Palavras-chave: Contração Muscular. Contração Isométrica. Reprodutibilidade dos Testes. Dinamômetro de Força Muscular. Eletromiografia.

\section{Introduction}

Muscle co-contraction is the simultaneous contraction of two or more antagonist muscles around a joint $(1-3)$. This phenomenon has been used to qualitatively and quantitatively assess human motor behavior in different situations such as gait, reach, jump and stability disorders $(4,5)$.

Advancing age prompts greater muscle co-contraction. One possible explanation for this finding is that co-contraction is a form of compensation for the reduction in muscle strength and atrophy of muscle fibers that accompany aging $(6,7)$.

Surface electromyography (EMG), an efficient tool to assess muscle activity, is also used for quantitative and qualitative evaluation of the co-contraction. The signal captured and recorded by this instrument corresponds to the sum of action potentials of motor units generated by voluntary and reflex muscle action, captured by electrodes placed on the surface of muscles (4 - 9).

One of the greatest obstacles to using this technique is the natural variability of electrical signals between individuals and muscles. Normalization, involving the expression of EMG data in relation to percentage of a reference value during a standardized and reproducible condition $(8,10,11)$, is a prerequisite for reducing the intrinsic and extrinsic factors that contribute to signal variability. This procedure makes it possible to compare EMG data between individuals, muscles, different collection days and different studies $(8,11$ - 15).

Reflecting the unease in the scientific community in relation to the topic, several techniques for normalizing electromyographic signals during static and dynamic activity have been extensively debated 
and thoroughly reviewed $(12,16$ - 27). Of these, the most frequently investigated are maximum voluntary isometric contraction (MVIC) $(10,11)$ and peak electrical activity (PEA) during the specific motor act.

MVIC, the most widely used in research $(12,15$, $20,28,29)$, is the normalization method suggested by the guide entitled Surface Electromyography for the Non-Invasive Assessment of Muscles (SENIAM) (10). It allows us to determine the percentage of muscle activation in relation to its maximum capacity (100\%) $(12,30)$. However, MVIC depends on the maximum recruitment of all the motor units which, in turn, depends on a number of factors, such as the individual's training level, ability to activate the muscle $(12,30)$, understanding, motivation and pain level $(22,28,31)$. Furthermore, MVIC is performed in a condition of isometry, while dynamic activities encompass cycles of concentric and eccentric activations that require specialized equipment, and prolonged collection times $(12,18,21,32$ - 35).

For this reason, recent years have seen considerable investment in incorporating MVIC normalization as the predominant, with a number of studies published on alternative models to MVIC normalization in dynamic activities, including average or submaximal activations during specific dynamic activities (12, 16 - 18, 20, 22, 23, 26, 32, 35), submaximal isometric contractions (26), as well as maximal and isokinetic submaximal contractions $(19,26,32)$.

By contrast, normalization by peak electrical activity (PEA) during the specific motor act has been suggested by some investigators as an alternative for normalizing electromyographic signals during analysis of a dynamic event $(12,16$ - 18). Normalization by PEA also reduces collection time (21) and makes normalization possible in studies with children and populations unable to perform MVIC owing to cognitive impairment, neurological or musculoskeletal disease $(12,17,18)$.

Given the importance of measuring co-contraction in the study of human movement and establishing uniformity in the procedures used in electromyographic studies, it is necessary to determine the association between different normalization techniques, in order to confirm the comparisons made between studies using different techniques. Therefore, this study aimed to compare inter-subject variability between co-contraction indices of the vastus lateralis (VL) and biceps femoris (BF) muscles, normalized by MVIC and PEA, during gait in the elderly, and investigate the association between these indices.

\section{Methods}

This cross-sectional exploratory study was approved by the research ethics committee of the Federal University of Minas Gerais (protocol no. 045/01).

\section{Sample}

This is a non-probability convenience sample in which sampling size was not calculated. Sampling criteria were accepting to take part and meeting inclusion and exclusion criteria. A total of $30 \mathrm{commu}-$ nity-dwelling elderly women, aged between 65 and 80 years, and able to walk without an assistive gait device, participated in the study. They were recruited from the Physical Education in the Elderly Project (Projeto Educação Física na $3^{\mathrm{a}}$ idade) conducted at the School of Physical Education, Physical Therapy and Occupational Therapy of the Federal University of Minas Gerais (UFMG). All participants met the following inclusion criteria: age greater than or equal to 65 years, absence of acute neurological or rheumatic diseases, no history of hip or knee surgery, absence of cognitive impairment that compromises understanding of the tests, hip range of motion of at least $90^{\circ}, 100^{\circ}$ knee flexion and $5^{\circ}$ extension and absence of lower limb pain.

All participants gave their informed consent to take part in the study.

\section{Instrumentation}

An MP150WSW electromyograph (Biopac Systems ${ }^{\circledR}$, Goleta, California) was used to monitor the electrical activity of vastus lateralis (VL) muscles, consisting of the knee extensors $(16,33,34)$, and biceps femoris (BF), consisting of the knee flexors (16, 29). This device has two amplifiers connected to a microcomputer. The amplifiers have inlet impedance of 2 mega Ohms (M $\Omega$ ) and a Common Mode Rejection capacity of $1000 \mathrm{M} \Omega$. Two active surface electrodes (Ag/AgCl - 11.4mm diameter - TSD-150A - Biopac System), with bipolar configuration were placed $3 \mathrm{~cm}$ between the detection surfaces.

A Biodex System 3 Pro isokinetic dynamometer (Biodex Medical Systems, Shirley, New York), operated by a previously trained assessor, was used to obtain MVIC of the BF and VL muscles. 
Procedure

The participants were instructed to appear for testing, conducted on a single day, with clean skin, free of oil or moisturizers.

To characterize the sample, subjects were assessed for anthropometric and clinical aspects including age, body weight, height, body mass index and physical activity level, according to the American College of Sports Medicine (ACSM) (36), which considers as active those who engage in moderate physical activity for at least 30 minutes on most days of the week. To warm up, participants pedaled a stationary bicycle (Ergo-Fit 167, Baujahr, 2001) for 5 minutes at a comfortable speed (17).

After participants' skin was cleaned using cotton soaked in alcohol, the active surface electrode pairs were placed in accordance with Criswell (13). The grounding electrode was placed on the head of the ipsilateral fibula (13). The data were collected only on the dominant lower limb, defined as that which the individual uses to kick a ball.

To familiarize the subjects, they were asked to walk comfortably at a normal self-selected speed for a distance of $6 \mathrm{~m}$, in a straight line on a flat even surface. After familiarization, electrical muscle activity was collected during gait using EMG.

Immediately following collection of muscle activity, participants were seated on the isokinetic dynamometer for MVIC tests of the VL and BF with their trunk, pelvis and thighs stabilized and legs dangling, with a distance of $5 \mathrm{~cm}$ between the edge of the chair and popliteal fossa of $5 \mathrm{~cm}$. The rotational axis of the device was aligned with the lateral epicondyle of the femur and the arm of the lever fixed above the lateral malleolus. To obtain data for normalization of the electromyographic signals, subjects underwent MVC of the $\mathrm{VL}$ and BF muscles, in the isometric mode of the dynamometer, with the knee flexed at 20 and $100^{\circ}$, respectively. Four 6-second VL contractions were performed 1 minute apart. The first of these was submaximal, aimed at familiarization. After 2 minutes, the same procedure was conducted for BF muscles. Repetitions were monitored using EMG and, of the three maximal contractions, that which generated the greatest electromyographic activity of each muscle was analyzed.

The isokinetic device was calibrated before each test according to manufacturer`s instructions.
Data Reduction

Acqknowledge ${ }^{\circledR}$ software (Biopac Systems. Goleta, California) was used to process and analyze electromyographic activity. Electromyographic signals were collected at $1000 \mathrm{~Hz}$ with $20 \mathrm{~Hz}$ high-pass filters and $450 \mathrm{~Hz}$ low-pass filters $(19,33,37,38)$, then rectified and filtered (Butterworth - linear envelope) with a $20 \mathrm{~Hz}$ low-pass $(11,37)$.

The signals were normalized in two ways: by the Root Mean Square obtained in MVIC (11) and PEA of the same muscle and participant. The mean co-contraction value was obtained using a specific program in MATLAB $^{\circledR}$, proposed by Fonseca et al. (3), where the common area between the muscle activity curves of the muscle groups that were in simultaneous contraction was identified and quantified. This area was obtained by overlapping the electromyographic activity proportion curves of the muscles tested.

\section{Statistical Analysis}

Normal distribution of the variables was tested and confirmed by the Kolmogorov-Smirnov test.

Descriptive statistical analysis of anthropometric, demographic and co-contraction variables was conducted. In the case of co-contraction, coefficients of variation (CV) were also calculated.

To investigate the association between co-contraction normalized by MVIC and PEA, the data were plotted on a dispersion diagram in order to verify the existence of a tendency to correlation. Based on the tendency to linearity observed, a liner model (simple regression) was fit to estimate the possibility of prediction. In this model, normalization by PEA was considered the dependent variable and by MVIC the independent variable. Analysis of residues was carried out after all the conditions required for regression analysis were met. The coefficient of determination $\left(\mathrm{R}^{2}\right)$ was also calculated to check the extent to which variation in normalization by MVIC explains the variation in normalization found by PEA.

A significance level of $p<0.05$ was adopted. Analyses were performed using the GraphPad Prism 5.0 statistical package.

\section{Results}

Of the 64 elderly assessed, 34 did not take part in the study for the following reasons: presence of 
neurological disease (6), acute rheumatic disease (15), previous hip surgery (3), previous knee surgery (9), and presence of cognitive impairment that compromises the tests (1). Thus, the final sample consisted of 30 elderly women. The anthropometric aspects of the participants are described in table 1 .

Table 1 - Anthropometric aspects of the sample $(\mathrm{n}=30)$

\begin{tabular}{lcc}
\hline \multicolumn{1}{c}{ Variables } & Mean $( \pm$ SD)** & Min - Max \\
\hline Age (years) & $70.33( \pm 3.69)$ & $65-79$ \\
Body mass $(\mathrm{kg})$ & $68.05( \pm 11.09)$ & $53-88$ \\
BMl $\left(\mathrm{Kg} / \mathrm{m}^{2}\right)$ & $26.84( \pm 4.92)$ & $18.13-39.11$ \\
\hline
\end{tabular}

Note: SD: standard deviation; BMl: body mass index. Source: Study data.

According to the ACSM, $53.33 \%$ of the participants were classified as active and $46.67 \%$ sedentary. Electromyographic data showed no outliers. Descriptive statistical analysis (mean \pm SD) and CV of non-normalized co-contraction were $0.13 \pm 0.09$ (CV $=69.3 \%$ ). Normalization by PEA and MVIC were $0.054 \pm 0.016(\mathrm{CV}=30.4 \%)$ and $0.09 \pm 0.044(\mathrm{CV}=$ $48.9 \%)$, respectively. The $\mathrm{CV}$ results are illustrated in Figure 1, which shows that the variation in data normalized by PEA was visibly lower than that produced by normalization using MVIC.

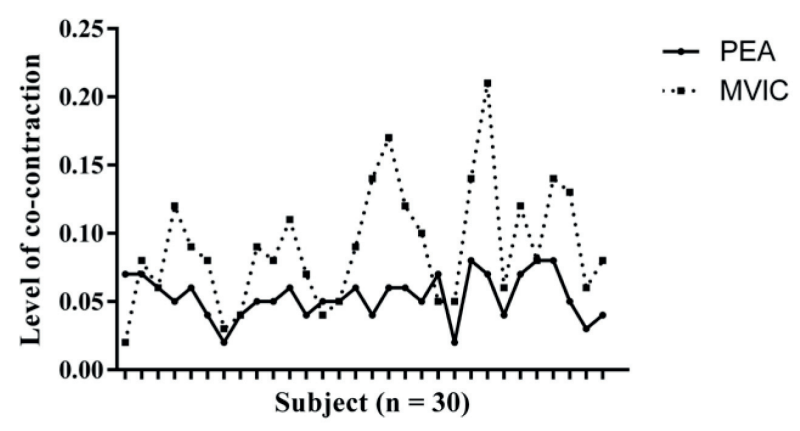

Figure $\mathbf{l}$ - Variations in vastus lateralis and biceps femoris co-contraction levels during gait, normalized by peak electrical activity (PEA) and maximal voluntary isometric contraction (MVIC) $(n=30)$.

Note: Study data.

Linear regression analysis produced the following prediction model: $\mathrm{PEA}=0.04+0.16 \mathrm{x}$ MVIC. The goodness of fit of the regression model was statistically significant $(\mathrm{p}=0.02)$. The confidence level $(95 \% \mathrm{CI})$ for the intercept was from 0.02 to 0.29 and for MVIC from 0.03 to 0.06 . These results suggest that an increase of 1 unit in MVIC corresponds to a rise of 0.16 in PEA, that is, a $100 \%$ variation in MVIC corresponds to only $16 \%$ in PEA. These data are consistent with the coefficient of determination found $\left(R^{2}=17 \%\right)$. The dispersion diagram, straight line of regression and the respective $95 \%$ confidence intervals are presented in Figure 2.

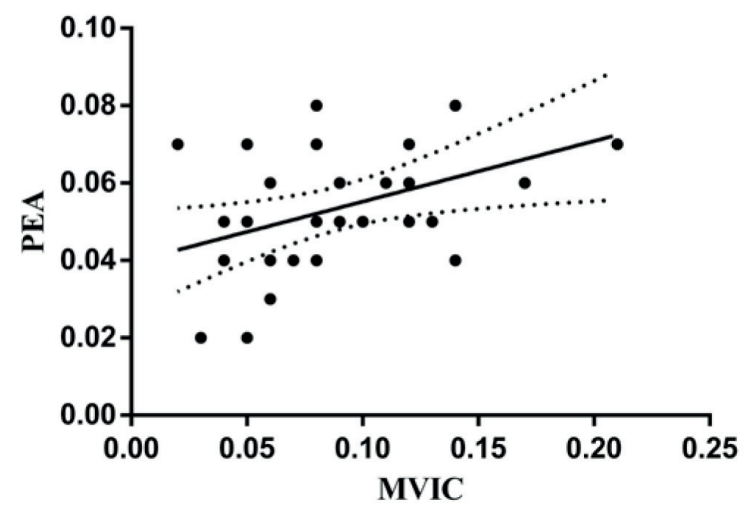

Figure 2 - Dispersion diagram and straight line of regression (with the respective 95\% confidence intervals) howing the level of co-contraction normalized by peak electrical activity (PEA) and maximum voluntary isometric contraction (MVIC) $(n=30)$ in gait.

Note: Study data.

\section{Discussion}

Given that an absence of adequate familiarization can cause a 20 to $30 \%$ loss of MVIC capacity (11), particular care was taken to familiarize the volunteers, eliminating inadequate data.

Since the objective was to collect maximal electrical muscle activity during MVIC, the position adopted in this study aimed at exposing the muscles tested to a condition of shortened active insufficiency, such that the muscle recruited the maximum number of motor units to generate MVIC) (39), ensuring an electromyographic recording that revealed the maximum possible contraction. Rutherford et al. (15), however, in a study aimed at verifying the existence of a difference in the amplitude of electrical activity during a series of maximal contractions at various 
knee angles and body positions, concluded that the greatest VL activation occurred at an amplitude of $45^{\circ}$ knee flexion in the sitting position or $15^{\circ}$ knee flexion in the supine position. The same authors concluded that the highest FB activation occurred at an angle of $15^{\circ}$ knee flexion in the supine position. The study, however, did not assess positions that placed muscles in shortened active insufficiency. Therefore, the choice of angle and position for MVIC may cause a methodological error, requiring further studies to determine the best position for maximum electrical activation of each muscle.

Given that inter-subject CV is inversely related to reproducibility, this index has been widely used in studies on the normalization of EMG data, and as a criterion for selecting a particular normalization method $(12,16-20,31,32,35)$. The inter-subject CV values of the present study showed that both forms of normalization reduced the variation in data when compared with non-normalized data. However, normalization by PEA exhibited a lower CV than that of MVIC. These results are in line with those reported in a number of studies showing less inter-subject variability with normalization by PEA compared with MVIC or other normalization methods $(16-18,26$, 32 ). This led some authors to consider PEA more appropriate in representing data (18), while others report that a lower CV is not necessarily good, since variability is necessary to identify differences (17). Moreover, even though PEA is a viable method for normalizing EMG data of patients with pain and neurological disorders, it tends to produce an electromyographic pattern that may infer unreal group homogeneity by removing real biological variations in EMG files during various activities, including gait $(16,17,26,31,32)$.

Furthermore, since PEA is obtained during the task under study, it does not provide the researcher or specialist with the required degree of muscle activation during gait or some other task, in relation to what the muscle is capable of generating $(12,16$ - 18). The only methods with the potential to reveal this information are normalization by maximal voluntary isometric or isokinetic contractions $(16,17,26$, 32 ), but both have exhibited higher CV in studies, primarily the latter $(26,32)$. Although the former conserves the natural biological variability of EMG data, it can cause discomfort, in addition to depending on psychological factors $(22,28,31)$ and training of individuals $(12,30)$. Because of this difficulty in controlling and monitoring the participant's exertion, it might not generate the maximum activity possible. This will result in higher EMG values than those normalized by PEA and also impacts the CV, which is significantly affected by the way in which MVIC is processed $(15,20,26)$.

The prediction model generated by linear regression showed that a $100 \%$ variation in data normalized by MVIC results in only a $16 \%$ variation in data normalized by PEA, and that the variation in normalization by MVIC accounts for only $17 \%$ of the variation in normalization by PEA and vice versa. These findings demonstrate the need for caution when comparing studies that used different techniques to normalize data $(12,18)$.

No studies were found that clearly described the prediction models used for data normalization. Therefore, it was not possible to compare these results. Nevertheless, we suggest that to make comparisons between EMG data from VL and FB cocontraction normalized by MVIC during gait and those normalized by PEA, conversion must first be performed using the prediction model obtained.

\section{Conclusions}

The variation in data normalized by PEA was lower than that produced via normalization by MVIC. Furthermore, a $100 \%$ variation in data normalized by MVIC results in only $16 \%$ variation in data normalized by PEA, and the variation in normalization by MVIC accounts for only $17 \%$ variation in normalization by PEA and vice versa. Caution is therefore recommended when comparing studies that used different techniques to normalize electromyographic data.

It is important to underscore that the results of this study refer to co-contraction of VL and FB muscles during the gait of asymptomatic elderly women. Thus, the conclusions of this study apply only to this scenario and cannot be generalized. Moreover, this investigation conducted measurements on a single day. Therefore, it is recommended that additional studies with the same objective be conducted with different age groups, tasks, muscles and days. 


\section{References}

1. Nardo FD, Mengarelli A, Maranesi E, Burattini L, Fioretti S. Assessment of the ankle muscle co-contraction during normal gait: A surface electromyography study. J Electromyogr Kinesiol. 2015;25:347-54.

2. Lametti DR, Houle G, Ostry DJ. Control of movement variability and the regulation of limb impedance. J Neurophysiol. 2007;98(6):3516-24.

3. Fonseca ST, Silva PLP, Ocarino JM, Ursine PGS. Análise de um método eletromiográfico para quantificação de co-contração muscular. Rev Bras Cien e Mov. 2001;9(3):23-30.

4. Fallah-Yakhdani HR, Abbasi-Bafghi H, Meijer OG, Bruijn SM, van den Dikkenberg N, Benedetti MG, et al. Determinants of co-contraction during walking before and after arthroplasty for knee osteoarthritis. Clin Biomech. 2012;27(5):485-94.

5. Lee HH, Lin CW, Wu HW, Wu TC, Lin CF. Changes in biomechanics and muscle activation in injured ballet dancers during a jump-land task with turnout. J Sports Sci. 2012;30(7):689-97.

6. Wang Y, Watanabe K, Asaka T. Age effects on multimuscle modes during voluntary body sway. Res Sports Med. 2015;23(1):88-101.

7. Nelson-Wong E, Appell R, McKay M, Nawaz H, Roth J, Sigler R, et al. Increased fall risk is associated with elevated co-contraction about the ankle during static balance challenges in older adults. Eur J Appl Physiol. 2012;112(4):1379-89.

8. Merletti R, Aventaggiato M, Botter A, Holobar A, Marateb H, Vieira TM. Advances in surface EMG recent progress in detection and processing techniques. Crit Rev Biomed Eng. 2010;38(4):305-45.

9. Kellis E, Katis A. Hamstring antagonist moment estimation using clinically applicable models: Muscle dependency and synergy effects. J Electromyogr Kinesiol. 2008;18:144-53.

10. Hermens HJ, Freriks B, Disselhorst-Klug C, Rau G. Development of recommendations for SEMG sensors and sensor placement procedures. J Electromyogr Kinesiol. 2000;10(5):361-74.

11. Standards for reporting EMG. J Electromyogr Kinesiol. 1996;6(2):III-IV.
12. Albertus-Kajee Y, Tucker R, Derman W, Lambert M. Alternative methods of normalising EMG during cycling. J Electromyogr Kinesiol. 2010;20(6):1036-43.

13. 13. Criswell E. Cram's introduction to surface electromyography. 2nd ed. Ontario (Canada): Aspen; 2010.

14. Lehman GJ, McGill SM. The importance of normalization in the interpretation of surface electromyography: a proof of principle. J Manipulative Physiol Ther. 1999;22(7):444-6.

15. Rutherford DJ, Hubley-Kozey CL, Stanish WD. Maximal voluntary isometric contraction exercises: a methodological investigation in moderate knee osteoarthritis. J Electromyogr Kinesiol. 2011;21(1):154-60.

16. Balshaw TG, Hunter AM. Evaluation of electromyography normalisation methods for the back squat. J Electromyogr Kinesiol. 2012;22(2):308-19.

17. Bolgla LA, Uhl TL. Reliability of electromyographic normalization methods for evaluating the hip musculature. J Electromyogr Kinesiol. 2007;17(1):102-11.

18. Albertus-Kajee Y, Tucker R, Derman W, Lamberts RP, Lambert MI. Alternative methods of normalising EMG during running. J Electromyogr Kinesiol. 2011;21(4):579-86.

19. Ball N, Sucurr J. An assessment of the reliability and standardisation of tests used to elicit reference muscular actions for electromyographical normalization. J Electromyogr Kinesiol. 2010;20(1):81-8.

20. Norcross MF, Blackburn JT, Goerger BM. Reliability and interpretation of single leg stance and maximum voluntary isometric contraction methods of electromyography normalization. J Electromyogr Kinesiol. 2010;20(3):420-5.

21. Nishijima Y, Kato T, Yoshizawa M, Miyashita M, Iida $\mathrm{H}$. Application of the segment weight dynamic movement method to the normalization of gait EMG amplitude. J Electromyogr Kinesiol. 2010;20(3):550-7.

22. Murley GS, Menz HB, Landorf KB, Bird AR. Reliability of lower limb electromyography during overground walking: a comparison of maximal- and sub-maximal normalisation techniques. J Biomech. 2010;43(4):749-56. 
23. Chapman AR, Vicenzino B, Blanch P, Knox JJ, Hodges PW. Intramuscular fine-wire electromyography during cycling: repeatability, normalisation and a comparison to surface electromyography. J Electromyogr Kinesiol. 2010;20(1):108-17.

24. Farina D, Cescon C, Merletti R. Influence of anatomical, physical, and detection-system parameters on surface EMG. Biol Cybern. 2002;86(6):445-56.

25. Hunter AM, St Clair GA, Lambert M, Noakes TD. Electromyographic (EMG) normalization method for cycle fatigue protocols. Med Sci Sports Exerc. 2002;34(5):857-61.

26. Burden A, Bartlett R. Normalisation of EMG amplitude: an evaluation and comparison of old and new methods. Med Eng Phys. 1999;21(4):247-57.

27. Kollmitzer J, Ebenbichler GR, Kopf A. Reliability of surface electromyographic measurements. Clin Neurophysiol. 1999;110(4):725-34.

28. Ha SM, Cynn HS, Kwon OY, Park KN, Kim GM. A reliability of electromyographic normalization methods for the infraspinatus muscle in healthy subjects. J Hum Kinet. 2013;36:69-76.

29. Branco VR, Negrão Filho RF, Padovani CR, Azevedo FM, Alvez N, Carvalho AC. Relação entre a tensão aplicada e a sensação de desconforto nos músculos isquiotibiais durante o alongamento. Rev Bras Fisioter. 2006;10:465-72.

30. Clarys JP. Electromyography in sports and occupational settings: an update of its limits and possibilities. Ergonomics. 2000;43(10):1750-62.

31. Burden A. How should we normalize electromyograms obtained from healthy participants? What we have learned from over 25 years of research. J Electromyogr Kinesiol. 2010;20(6):1023-35.

32. Burden AM, Trew M, Baltzopoulos V. Normalisation of gait EMGs: a re-examination. J Electromyogr Kinesiol. 2003;13(6):519-32.

33. Lamy JC, Iglesias C, Lackmy A, Nielsen JB, Katz R, Marchand-Pauvert V. Modulation of recurrent inhibition from knee extensors to ankle motoneurones during human walking. J Physiol. 2008;586(24):5931-46.
34. Kuznestsov S, Popov DV, Borovik AS, Vinogradova OL. Wavelet analysis of $\mathrm{m}$. vastus lateralis surface EMG activity in incremental test till exhaustion using bicycle and knee extension exercises. Fiziol Cheloveka. 2011;37(5):129-36.

35. Rota S, Rogowski I, Champely S, Hautier C. Reliability of EMG normalisation methods for upper-limb muscles. J Sports Scien. 2013;31(15):1696-704.

36. Whaley MH, Brubaker PH, Otto RM, Armstrong LE. ACSM Guidelines for exercise testing and prescription. 7th ed. Philadelphia: Lippincott Williams \& Wilkins; 2006.

37. Law LF, Krishnan C, Avin K. Modeling nonlinear errors in surface electromyography due to baseline noise: a new methodology. J Biomech. 2011;44(1):202-5.

38. McDonald AC, Sanei K, Keir PJ. The effect of high pass filtering and non-linear normalization on the EMGforce relationship during sub-maximal finger exertions. J Electromyogr Kinesiol. 2013;23(3):564-71.

39. Anderson KG, Behm DG. Maintenance of EMG activity and loss of force output with instability. J Strength Cond Res. 2004;18(3):637-40.

Received in $05 / 20 / 2015$ Recebido em 20/05/2015

Approved in 12/16/2015 Aprovado em 16/12/2015 